\title{
Prevention and Management of Sport-Related Concussions in Uganda: A Case Study
}

\author{
Samuel K Lubega ${ }^{1, *}$, Mike Lambert ${ }^{1}$, Timothy Makubuya ${ }^{2}$, Shelina Babul ${ }^{3}$, Haruna Muwonge ${ }^{4}$, \\ Robert Zavuga $^{5}$, Josephine Kasolo ${ }^{4}$, Joseph Kalanzi ${ }^{6}$ \\ ${ }^{1}$ Department of Human Biology, University of Cape Town, Cape Town, South Africa \\ ${ }^{2}$ Department of Educator Preparation and Leadership, University of Missouri-St. Louis, St. Louis, USA \\ ${ }^{3}$ Department of Pediatrics, University of British Columbia, Vancouver, Canada \\ ${ }^{4}$ Department of Physiology, Makerere University, Kampala, Uganda \\ ${ }^{5}$ Medical Commission, Uganda Olympic Committee, Kampala, Uganda \\ ${ }^{6}$ Emergency Medicine Division, Makerere University, Kampala, Uganda \\ *Corresponding author: lbgsam001@myuct.ac.za
}

Received February 14, 2019; Revised March 18, 2019; Accepted April 24, 2019

\begin{abstract}
Head injuries in sports often go unnoticed and untreated with a risk of increasing the severity of neurological difficulties for affected athletes. While there is much research on athletes in developed countries, the data on athletes from developing countries is lacking. Using a descriptive case study approach, this report focuses on concussions from four main sports (football, athletics, basketball and rugby). Emphasis was placed on those athletes who had been identified with a sport-related concussion (SRC). The phases of emergency, intermediate, rehabilitative, and return to sports participation were considered in this study. Three SRC cases from both male and female athletes were observed and interviewed for post-injury management from the emergency phase to return to sports participation. There was evidence of lack of specific pre-season screening of athletes for concussion history and standard care for concussed athletes in all the three cases observed using the best medical practice framework. Our study shows barriers such as knowledge among the sports resource providers; a law and policies to mandate care, and the absence of specific facilities for managing athletes with concussions. Implementation of sports health care policies is necessary to mandate care for athletes. Strategies for prevention and management of concussions are necessary, especially through increasing the awareness and knowledge using the Concussion Awareness Training Tool (CATT). Further studies with larger samples are encouraged to ascertain the magnitude of existing barriers.
\end{abstract}

Keywords: concussion, knowledge, prevention, emergency, rehabilitation, best medical practice

Cite This Article: Samuel K Lubega, Mike Lambert, Timothy Makubuya, Shelina Babul, Haruna Muwonge, Robert Zavuga, Josephine Kasolo, and Joseph Kalanzi, "Prevention and Management of Sport-Related Concussions in Uganda: A Case Study.” American Journal of Sports Science and Medicine, vol. 7, no. 2 (2019): 34-39. doi: 10.12691/ajssm-7-2-2.

\section{Introduction}

Concussions have received increasing attention as a sport-related injury often due to its under-diagnosed and potential long term consequences [1,2]. The proper recognition of an event that could result in a concussion is the first step to standardize diagnosis, treatment and management. Appropriate treatment and management for concussion can minimize the recovery period $[3,4,5]$ and support the athlete to successfully return to sport participation without a high risk of an immediate re-injury [6,7]. However, literature on the management of sports concussion among sports participants from developing countries like Uganda, is still lacking.

In United States, the Institute of Medicine and National Research Council reported that young-adults were more predisposed to concussion injuries [8]. In Uganda, 77\% of the Ugandan population is below the age of 30 years, with a large number of professional athletes at secondary and tertiary education institutions [9]. Moreover, the risk for head related injuries such as concussions varies by gender [10], but it is possible that poor management of concussion cases would increase the severity of long term effects regardless of gender. In fact, substantive declines in cognitive and motor function in later life, personality changes, and dementia have been reported. In some cases, athletes have also committed suicide [11,12]. Evidence suggests gender differences in various attributes for the usage of personal protective equipment in youth, high school, and collegiate soccer players in the U.S. [13]. It is possible, that sports participants in Uganda would be at a much larger disadvantage sorely based on scarce availability of personal protective gear and relevant standard health care units. A major concern for concussions is chronic traumatic encephalopathy (CTE), including its other form dementia pugilistica associated 
with boxing [14,15,16,17,18]. This condition may be related to the frequency of sub-concussive blows, intensity of those hits, or some other trigger. It remains a mystery since not all the athletes that experience sub-concussive blows develop this condition [18]. In the U.S., high profile cases have exposed the mismanagement of concussion that sometimes resulted in fatal consequences at professional level $[19,20,21,22]$. A settlement of nearly $\$ 1$ billion US (£680m; €940m) was granted as a preliminary approval by the judge in a case against the National Football League brought by former football players over failure to inform them of the risks of concussion $[23,24,25]$. Similar litigations followed with athletes from the National Collegiate Athletic Association (NCAA) and National Hockey League [26]. Although injuries do not happen all the time when an individual participates in contact sports, the prevention of devastating and fatal consequences arising from a head collision should be emphasized with a system of managing day to day events during training or competitions. In addition, there must be adequate plans for the identification of populationspecific risk factors, to manage these injuries efficiently. Evidence on effective concussion prevention programs is still scant [26,27]. However, developing countries like Uganda, should establish relevant protocols. Guided by the Consensus on Concussion Statement [11], this study utilizes a population- specific best medical practice framework for Uganda. When the injury occurs, recommended use of standard on field-recognition, investigations/assessments, treatment and return to sports participation are crucial [11]. Among the underlying complex and long-term issues however, involves understanding the adverse issues specific to athlete populations [11]. The goal of this study was to document current concussion management and prevention practices and demonstrate a viable best medical practice framework to be followed to prevent and manage sport-related concussion (SRC) injury in Uganda.

\section{Methodology}

A descriptive prospective cohort study design was used to establish and document injury management behavior. The data were collected in a six month period through the various phases from emergency to returning athletes to sports participation using the best practice framework model (Figure 1). The study participants were athletes that were selected using purposive sampling from four of the 48 currently registered sports associations (Athletics, Basketball, Football and Rugby) by Uganda National Council for Sports (NCS). These associations have registered the highest number of participants and clubs to participate in national competitions. Athletes, coaches, managers and health care providers were informed and consent was obtained for the observation of their practices during training and competition for 6-month study period. This study was approved by the Institutional Review Board (IRB) of the University of Cape Town (HRECREF: 584/2014) the School of Public Health, Makerere University (MakSoPH protocol 242) and Uganda National Council of Science and Technology in Kampala, Uganda (SS3626). Further permissions were obtained from the Uganda National Council of Sports (UNCS), Uganda Olympic Committee (UOC) and from the four federation management boards.

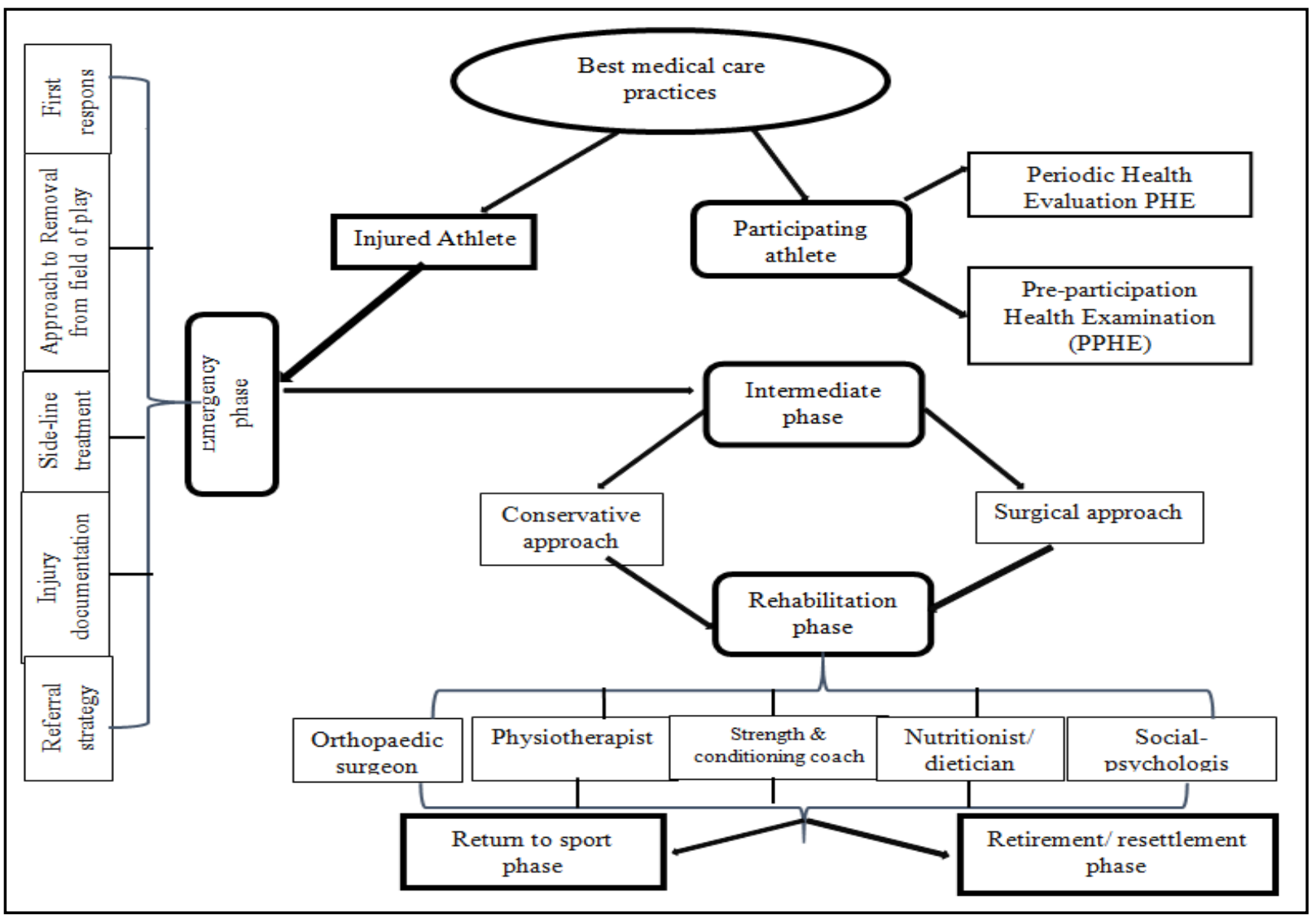

Figure 1. Best medical practice framework for athletes’ sports participation in Uganda 
The data capture form consisted of five sections: demographic information, the preventive care, emergency care, intermediate, and rehabilitation care and return to sports participation care sections. During the study period, seventy-five athletes were identified and included for particular injury observation. No data were collected at the resettlement phase, as all three cases returned to play. The content and format of the capture form and framework tool was assessed by a sports injury prevention scientific group in the Division for Exercise Science and Sports Medicine (ESSM; www.essm.ac.za), at the Sports Institute of South Africa, University of Cape Town. The design process of the tool was validated by this scientific group upon incorporating specific feedback.

The immediate injury data contained: demographic information and emergency injury management information that were documented by the researchers through observation and interview. The consented athletes accepted daily calls for the next 15 days, and then a weekly call thereafter, until his or her return to sports participation.

Data collection and analysis at different phases was conducted as depicted by the framework (Figure 1) as follows;

1. Initially, the concussed athletes were asked if they had had pre-participation examination (PPE) or periodic health examination (PHE) before participating in the sporting event.

2. The emergency care phase activities were determined at 5 checkpoints: I) first aid response, II) side-line services; III) injury documentation IV) referral strategy and V) appropriate removal and follow up.

3. The intermediate care phase activities were evaluated by two main outcomes: The utilization of a conservative treatment approach or the application of necessary surgical procedures.

4. The rehabilitation phase activities were evaluated based on the appropriate engagement by the specialists who are supposed to provide sports healthcare services.

5. In the return to play phase, the framework recognizes the necessity of the coaches for verification of athlete recovery [28].

Table 1. Demographic Characteristics of Concussed Athletes

\begin{tabular}{ccccc}
\hline $\begin{array}{c}\text { Concussion } \\
\text { Case }\end{array}$ & Gender & Age & Sport & $\begin{array}{c}\text { Time of } \\
\text { Injury }\end{array}$ \\
\hline Case 1 & Male & 26 years & Rugby & $\begin{array}{c}\text { During } \\
\text { Competition }\end{array}$ \\
\hline Case 2 & Male & 20 years & $\begin{array}{c}\text { Football } \\
\text { (Soccer) }\end{array}$ & $\begin{array}{c}\text { During } \\
\text { Competition }\end{array}$ \\
\hline Case 3 & Female & 32 years & Basketball & $\begin{array}{c}\text { During } \\
\text { Competition }\end{array}$ \\
\hline
\end{tabular}

\section{Results}

\subsection{Case 1}

The first incident involved a 26-year-old male rugby player. The player was concussed after colliding with another player and subsequently became unconscious during the rugby match. The player did not have a PPE/PHE conducted on him. The player was immobilized on a spinal board immediately by the health care providers from the ambulance stationed at the field and taken to the hospital. The athlete was later contacted to confirm the treatment services at the hospital and the player reported that he did not have any further medical investigations conducted on him. He was advised by the attending physician to continue resting. On his return to the hospital, after 30 days, he was cleared by the same physician to return to sports participation. The player did not report undergoing any rehabilitative program or assessment before he fully returning to sports participation during the 30 days rest at home.

\subsection{Case 2}

The second incident involved a 20-year-old male football/soccer player. The player was concussed and wounded on the forehead during a football match. He had not undergone any form of PHE/PPE before the match. During the emergency phase of the injury, he was managed by the team physiotherapist. The injury was managed by ice compression and also with gauze and a bandage to control the bleeding from the laceration sustained in the face. He was later referred to the hospital for further laceration management. The player's wound was sutured at the hospital and was given medication (did not disclose) upon discharge. The player did not report having any further medical investigations. He was not given any information about concussion injury before he was discharged from the hospital. After 12 days, he was cleared by the physician to return to sport training. The player mentioned that his clearance did not involve any tests. Before he returned to sports participation, no further tests or rehabilitative exercises were performed by any medical specialists and he only reported that a check-up was done to confirm healing of the wound by the hospital personnel.

\subsection{Case 3}

This involved a 32-year-old female basketball player. The player hit her head against the knee of her opponent during a basketball competition and became unconscious. She was not put on a stretcher, but instead was immediately carried by the physiotherapist, nurse, and teammates to a quiet room. She regained consciousness in the room beside the basketball court after ten minutes. On observation, she was tested with the Sports Concussion Assessment Tool 3 (SCAT3) questions [29] and was advised by the physiotherapist not to return to the game. The player had not undergone any medical evaluation (PPE/PHE) before participating in sports. After twenty minutes she sat on the bench beside the basketball court, watched the game and went home by herself using public transportation in a taxi. The following morning, she consulted a team physician who prescribed her undisclosed medications and advised her to rest. The same player reported a history of a previous SRC 3-months prior to this incident. She reported that she felt that the present concussion was more severe compared to the first concussion. She reported resting for 14 days before her 
return-to- sports participation following the previous concussion. When she returned to sports participation, she was allowed to play for four to five minutes in order to follow player substitution according to basketball rules [30].

\section{Discussion}

The primary goal of the study was to document the current concussion prevention and management practices in Ugandan sports, and demonstrate the utilization of a viable framework for best medical practices for Ugandan sports. Using this established and validated framework (Figure 1), three concussed cases were identified and followed during their recovery until they were allowed to return to sport participation phase. Our study provides foundation for studying SRC in Uganda, and particularly within the best medical practice framework.

\subsection{Best Medical Practices}

There is currently insufficient data globally providing specific best medical practices in identifying injury risks [31,32]. Using the best medical practice framework (Figure 1), none of concussed athletes in our study, had any form of PPE/PHE. Despite the lack of formal guidelines on how to prevent concussion, the IOC consensus statement recommends the use of PPE to mitigate athlete's injuries [33]. The existence of some form of PPE enforcements by elite sports teams in the European Soccer leagues, been well documented [34]. It is possible that their success is attributed to the existence of stringent policy and application of fines for noncomplying teams. It is therefore possible that the implementation of a similar policy in Uganda, coupled with a requirement of non-complaint teams to pay high fines, seems a plausible solution. Some scholars have suggested that PPE/PHE assists in detecting conditions that would predispose the athlete to injury or illness, thereby, providing a strategy to prevent injuries. Moreover, the clearance of an athlete should be based on the outcome of the evaluation [35].

Internationally, there are also institutional policies that help to enforce screening of athletes' history of head injuries before sports participation in a bid to provide a strong support for prevention of concussion injury [36]. For example, in U.S.A, medical and athletic organizations encourage the evaluation of persons with musculoskeletal problems, history of concussion, or other neurologic disorders [35]. In addition, the use of awareness in form of medical education programs is recommended by concussion research scholars $[37,38]$. However, divergent implementation as a result of state and sports leagues has been highlighted as a cause of failure for the NCAA concussion prevention education, leading to calls for evaluation of the education programs [36]. One of the essential elements of PPE/PHE is the opportunity for medical professionals to talk to athletes directly about their health problems. This can also be used as an opportunity to screen for injury risk [39]. Besides, this strategy can help to identify athletes at risk of concussion or second concussion injury [38].

\subsection{Emergency Phase}

When an athlete receives a jolt or blow on the head, this framework recognizes the implementation of the emergency phase. During the study period, data were recorded on the activities based on the five elements of; I) first aid response, II) side-line services; III) injury documentation and IV) referral strategies and V) appropriate removal and follow up care. Our results showed that only one athlete (case 2) was referred immediately to the nearby emergency department for further management, possibly due to unconsciousness. The athletes who reported a past concussion, was however not immediately referred to the emergency room, despite the concern of a prior concussion being a high risk factor [40]. It is possible that the absence of a PPE/as components of the best medical practices framework makes it harder for athletes to remind their coaches and team personnel of this risk. In other cases, it is possible that concussions are deliberately concealed to avoid being left out of the game or accused of faking or playing lazy [41]. The presence of a licensed medical professional or a knowledgeable and trained coach in areas of concussion management is vital, in provision of first aid, documentation of injury, side-line management, removal, and referral and follow up. In fact, in some cases, the absence of such necessary support is ground for litigation [42]. There is currently a dearth of sports injury litigations in Uganda, apart from the case of National Council of Sports vs. Peter Grace Sseruwagi [43]. While this doesn't occur often, there is a possibility that cases might increase like in other parts of the world [23,24,25]. In fact, requirements should be in place to manage concussion injury. For example, facilities appropriately set-up to provide room for medical assessment and alternative rest of the field for all injured athletes. These facilities should be staffed with properly trained professionals that understand the assessment processes that are guided by Sports Concussion Assessment Tool 5 (SCAT5) and Concussion Recognition Tool 5 (CRT5) [44].

Our findings suggest that there was a lack of adherence to current concussion best practice guidelines [11]. According to the 5th Consensus Statement on Concussion in Sport, athletes should be removed and normalized, and if necessary referred and immediately taken to the emergency room. In addition, there should be documentation of the concussion [11].

\subsection{Intermediate Phase}

There was no further concussion symptom evaluation by the hospital physician for the athlete referred to the emergency department. The results showed that the three athletes were seen by health professionals at a later stage, however, they were advised to continue with nonsupervised rest at home. This clearly shows that medical attention given to the athlete wasn't directed to specifically managing a concussion injury. For the case of football in Uganda, guidelines from the Federation of International Football Association (FIFA) recommend that following a proper referral, the athletes is re-evaluated using a comprehensive medical assessment approach [45]. This enables the health care team to establish the current 
clinical status to determine a need for further investigations. Our study identifies gaps in knowledge and practice, and recommends further implementation of effective education resources and training such as the Concussion Awareness Training Toolkit (CATT) nationally [46]. Furthermore, in order to address the knowledge gap, there is a need for the implementation of a country-specific concussion certification program for professionals working with athletes in Uganda.

\subsection{Rehabilitation Phase}

The process of recovery, and then return to sport participation after a SRC, follows a graduated stepwise rehabilitation strategy [11]. The principle guideline at this stage is to encourage activities at home without symptoms [11]. Then increase tolerance to physical and cognitive work, until the athlete is fit to full return to sports program activities symptom free [11]. Our study results, show that the rehabilitation process were inadequate for all the athletes reported in this study. Yet, the current guidelines for rehabilitating a SRC recommend a multidisciplinary team for the management of a confirmed case of concussion [11]. Overall, our results suggest insufficiency in the knowledge and practice of concussion injury management best practice guidelines in Uganda. The other barriers that may have influenced the injury management process are the appropriate sports facility medical rooms as well as health care policy on concussion management.

\subsection{Return to Sport Phase}

At this point, there are no guidelines applied for determining return to sport for concussed athletes in Uganda. Our study, suggests the implementation of national guidelines in returning to play based on SCAT 5, CRT5 and management of cases within the suggested framework. A series of guidelines as suggested by Cantu $[47,48]$ are useful in safe return to participation while others have been utilized for athletes in the U.S. for management of concussions [49,50]. Elsewhere, available evidence suggests the possibility of long lasting consequences of brain injury and the inability to return to sports, although further inquiry is warranted [51].

\section{Conclusion}

Our paper highlights the current prevention and management practices for SRC for Ugandan athletes from three sporting associations of football, basketball and rugby whose injuries can occurred during practice or competition. This study provides vital information for national health care policy makers, especially in Uganda to improve on the management of sports related head injuries. Using the best medical practices framework (Figure 1), athletes, coaches, managers and other sports health professionals can be empowered to utilize all the necessary resources and knowledge to prevent and manage concussion cases. We highlighted that proper utilization and viable prevention and management protocols require national regulatory and education policy, training, implementation and evaluation of implemented practices. Thus, this calls for a deliberate effort through a collaborative approach for both private and public stakeholders necessary to promote Ugandan sports. We realize that, this is a team and national effort for the implementation of this framework, and thus recommending the formulation of key policy and regulation with the mandate of a governing body.

\section{Acknowledgements}

The authors thank Dr. Rose Nassali (Former Permanent Secretary Ministry of Education and Sports-Uganda), Mr. Peter Ocheng (Commissioner for Higher EducationUganda), Eng. Charles Bakabulindi (State Minister for Sports- Uganda) and Mr. Peter Apita (Commissioner for Physical Education and Sports- Uganda) for securing funding for this project. The authors thank Ms. Joyce Mutiibwa for assistance rendered in collection of data. The authors gratefully acknowledge the cooperation of Uganda Athletics Federation, Federation of Uganda Basketball Association, Uganda Rugby Union and Federation of Uganda Football Association. The authors also acknowledge the support of medical staff of Uganda during this study. We wish to thank Tim Schmalz for conducting literature searches. This study was funded through Uganda's Ministry of Education and Sports' Independent Scholarship program 2014/2015 and University of Cape Town Post graduate Funding office 2014-2017.

\section{References}

[1] Conidi FX, Drogan O, Giza CC, Kutcher JS, Alessi AG, Crutchfield KE. Sports neurology topics in neurologic practice: A survey of AAN members. Neurol Clin Pract. 2014; 4(2):153-160.

[2] Kimbler DE, Murphy M, Dhandapani KM. Concussion and the adolescent athlete. J Neurosci Nurs. 2011; 43(6): 286-90.

[3] Conder RL, Conder AA. Sports-related concussions. N C Med J. 2015; 76(2):89-95.

[4] Scorza KA, Raleigh MF, O’Connor FG. Current concepts in concussion: evaluation and management. Am Fam Physician. 2012; 85(2): 123-32.

[5] Moser RS, Iverson GL, Echemendia RJ, et al. Neuropsychological evaluation in the diagnosis and management of sports-related concussion. Arch Clin Neuropsychol. 2007; 22(8): 909-916.

[6] Centers for Disease Control and Prevention (CDC). Traumatic brain injury in the United States: fact sheet. CDC website. www.cdc.gov/traumaticbraininjury/get_the_facts.html. Published June 2014. Accessed February 18, 2015.

[7] Centers for Disease Control and Prevention (CDC). What can I do to help prevent traumatic brain injury? CDC website. http://www.cdc.gov/traumaticbraininjury/prevention.html. Updated September 13, 2013. Accessed February 18, 2015.

[8] DePadilla L, Miller GF, Jones SE, Peterson AB, Breiding MJ. Self- reported concussions from playing a sport or being physically active among high school students, United States 2017. MMWR Morb Mortal Wkly Rep. 2018; 67(24): 682-685.

[9] Muwonge H, Zavuga R, Kabenge PA, Makubuya T. Nutritional supplement practices of professional Ugandan athletes: a crosssectional study. J Int Soc Sports Nutr. 2017; 14:41. Published 2017 Nov 13.

[10] Prien A, Grafe A, Rössler R, Junge A, Verhagen E. Epidemiology of Head Injuries Focusing on Concussions in Team Contact Sports: A Systematic Review. Sports Med 48 (4): 953-969, 2018.

[11] McCrory P, Meeuwisse W, and Johnston K, et al. Consensus statement on concussion in sport: the 3rd International Conference on Concussion in Sport held in Zurich, November 2008. Br J Sports Med 2009; 43(Suppl 1): i76-90. 
[12] Martin G (2016) Concussion \& Consequences: A Review. Ann Sports Med Res 3(2): 1064.

[13] King D, Hume PA, Brughelli M, et al. Instrumented mouthguard acceleration analyses for head impacts in amateur rugby union players over a season of matches. Am J Sports Med 2015; 43: 614-24?

[14] Maroon JC, Winkelman R, Bost J, Amos A, Mathyssek C, Miele V. Chronic traumatic encephalopathy in contact sports: a systematic review of all reported pathological cases. PLoS One. 2015; 10(2):e0117338. Published 2015 Feb 11.

[15] McKee AC, Stein TD, Kiernan PT, Alvarez VE. The neuropathology of chronic traumatic encephalopathy. Brain Pathol. 2015; 25(3):350-64.

[16] Lakhan SE, Kirchgessner A. Chronic traumatic encephalopathy: the dangers of getting "dinged". Springerplus. 2012; 1:2. Published 2012 Mar 12.

[17] Stern RA, Riley DO, Daneshvar DH, Nowinski CJ, Cantu RC, McKee AC. Long-term consequences of repetitive brain trauma: chronic traumatic encephalopathy. PM R 2011; 3: S460-7.

[18] Castellani RJ, Perry G, Iverson GL. Chronic effects of mild neurotrauma: putting the cart before the horse? J Neuropathol Exp Neurol. 2015; 74(6):493-9.

[19] Omalu BI, Hamilton RL, Kamboh MI, et al. Chronic traumatic encephalopathy (CTE) in a national football league player: case report and emerging medicolegal 215 practice questions. J Forensic Nurs 2010; 6: 40-6.

[20] Omalu BI, Fitzsimmons RP, Hammers J, et al. Chronic traumatic encephalopathy 214 in a professional American wrestler. J Forensic Nurs 2010; 6: 130-6.

[21] Omalu BI, DeKosky ST, Minster RL, et al. Chronic traumatic encephalopathy in a national football league player. Neurosurgery 2005; 57: 128-34; discussion 128-134.

[22] Omalu BI, Bailes J, Hammers JL, et al. Chronic traumatic encephalopathy, suicides 211 and parasuicides in professional American athletes: the role of the forensic pathologist. Am J Forensic Med Pathol 2010; 31: 130-2?

[23] Breslow JM. Concussion watch. PBS Frontline.2015 Retrieved from http://apps.frontline.org/concussion- watch/ - positions_2012.

[24] Breslow JM. What the NFL's new concussion numbers don't answer? PBS Frontline. 2016 Retrieved from http://www.pbs.org/wgbh/frontline/article/what-the-nfls-newconcussion-numbers-dont-answer/.

[25] Weinmeyer R. Concussion-related litigation against the National Football League. Virtual Mentor. 2014; 16(7): 552-8.

[26] Enniss TM, Basiouny K, Brewer B, et al. Primary prevention of contact sports-related concussions in amateur athletes: a systematic review from the Eastern Association for the Surgery of Trauma. Trauma Surg Acute Care Open. 2018; 3(1): e000153. Published 2018 Jun 20.

[27] Pachman S, Lamba A. Legal Aspects of Concussion: The Ever-Evolving Standard of Care. J Athl Train. 2017; 52(3): 186194.

[28] Babul S. Addressing the need for standardized concussion care in Canada: Concussion Awareness Training Tool. Can Fam Physician. 2015; 61(8):660-2.

[29] Hurtubise JM, Hughes CE, Sergio LE, Macpherson AK. Comparison of baseline and postconcussion SCAT3 scores and symptoms in varsity athletes: an investigation into differences by sex and history of concussion. BMJ Open Sport Exerc Med. 2018; 4(1):e000312. Published 2018 Mar 21.

[30] Strand SL. Post-concussive syndrome in a female basketball player: a case study. Open Access J Sports Med. 2013; 4: 123-5. Published 2013 May 14.

[31] Maffey L, Emery C. Physiotherapist delivered preparticipation examination; rationale and evidence. N Am J Sports Phy Ther.
2006; 1(4); 176-186.

[32] Sanders B, Blackburn TA, Boucher B. Preparticipation screening the sports physical therapy perspective. Int J Sports Phys Ther. 2013; 8(2): 180-93.

[33] Ljungqvist, A., Jenoure, P.J., Engebretsen, A.H., Alonso, J.M., Bahr, R., Clough, A.F., et al. The international olympic committee consensus statement on periodic health evaluation of Elite Athletes, March 2009. Clin. J. Sport Med. 19, 347-360.

[34] McCall, A., Dupont, G., Ekstrand, J. Injury prevention strategies, coach compliance and player adherence of 33 of the UEFA Elite Club Injury Study teams: a survey of teams' head medical officers. Br. J. Sports Med.2016; 50, 725-730.

[35] Mirabelli MH, Devine MJ, Singh J, Mendoza M. The preparticipation sports evaluation. Am Fam Physician 2015; 92.

[36] Kroshus E, Daneshvar DH, Baugh CM, Nowinski CJ, Cantu RC. NCAA concussion education in ice hockey: an ineffective mandate. Br J Sports Med. 2014; 48: 135-40.

[37] Echlin PS, Johnson AM, Riverin S, Tator CH, Cantu RC, Cusimano MD, et al: A prospective study of concussion education in 2 junior ice hockey teams: implications for sports concussion education. Neurosurg Focus, 2010, 29(5): E6

[38] Emery CA, Black AM, Kolstad A, et al. What strategies can be used to effectively reduce the risk of concussion in sport? A systematic review. Br J Sports Med 2017; 51: 978-984.

[39] McCrory P, Meeuwisse W, Dvorak J, et al Consensus statement on concussion in sport - the 5th international conference on concussion in sport held in Berlin, October $2016 \mathrm{Br} J$ Sports Med 2017; 51: 838-847.

[40] Abrahams S, Fie SM, Patricios J, et al. Risk factors for sports concussion: an evidence-based systematic review $\mathrm{Br} J$ Sports Med 2014; 48: 91-97.

[41] Semrud-Clikeman M, Klipfel KM. J Pediatr Neuropsychol 2016; 2:58.

[42] Broglio SP, Cantu RC, Gioia GA, et al. National Athletic Trainers Association position statement: management of sport concussion. J Athl Train. 2014; 49(2): 245-65.

[43] National Council of Sports v Peter Grace Sseruwagi [2004] UGHC 17 https://ulii.org/ug/judgment/high-court/2004/17.

[44] Echemendia RJ, Meeuwisse W, McCrory P, et al. The Concussion Recognition Tool 5th Edition (CRT5): Background and rationale Br J Sports Med 2017; 51: 870-871.

[45] https://resources.fifa.com/image/upload/football-emergencymedicine-manual-2nd-edition-2018 2674609.pdf?cloudid=pwkybrzpulzjofsbtt9n.

[46] Babul S, Korn P, Goldman R, et al. Preventing Adverse Concussion Outcome: The Online Concussion Awareness Training Toolkit (CATT). Br J Sports Med 2014; 48: 563-564.

[47] Cantu RC. Cerebral concussion in sport: management and prevention. Phys Sportsmed 1992; 14: 64-74.

[48] Cantu RC. Posttraumatic retrograde and anterograde amnesia: pathophysiology and implications in grading and safe return to play. J Athletic Training 2001; 36: 244-8.

[49] American Academy of Neurology. Practice parameter: the management of concussion in sports (summary statement). Report of the Quality Standards Subcommittee. Neurology 1997; 48: 581-5.

[50] Kelly JP, Nichols JS, Filley CM. Concussion in sports: guidelines for the prevention of catastrophic outcome. JAMA 1991; 266: 2867-9.

[51] Kathryn Y. Manning, Amy Schranz, Robert Bartha, Gregory A.Dekaban, Christy Barreira, Arthur Brown, Lisa Fischer, Kevin Asem, Timothy J. Doherty, Douglas D. Fraser, Jeff Holmes, Ravi S. Menon. Multiparametric MRI changes persist beyond recovery in concussed adolescent hockey players Neurology Nov 2017, 89 (21) 2157-2166. 